\title{
Identidades urbanas en Trilogía Sucia de La Habana de Pedro Juan Gutiérrez
}

\author{
Urban Identities in Pedro Juan Gutiérrez's \\ Dirty Havana Trilogy
}

David García-Reyes*

Sergio Ruiz García**

\begin{abstract}
Resumen: En este artículo se examinan algunas de las principales características en la construcción identitaria urbana de La Habana durante la década de los años 90. Tomando como eje principal la Trilogía Sucia de La Habana del escritor Pedro Juan Gutiérrez, se detectan las principales tipologías urbanas de La Habana, relacionadas fundamentalmente a las clases subalternas de Centro Habana. Todo ello enmarcado en un nuevo contexto histórico para la Cuba revolucionaria: el periodo especial en tiempos de paz.
\end{abstract}

Palabras clave: Periodo especial, identidad urbana, tipología urbana, La Habana, Pedro Juan Gutiérrez

\begin{abstract}
This paper shows the main characteristics of urban identity construction in Havana during the 1990s. The book Dirty Havana Trilogy by Juan Gutierrez explores different urban typologies of the subaltern classes of Centro Habana. The story of Gutierrez depicts a new historical context for Revolutionary Cuba: The Special Period in Times of Peace.
\end{abstract}

Keywords: Special Period, urban identity, urban typology, Havana, Pedro Juan Gutiérrez

Recibido: 05/06/2017

Aceptado: 28/07/2017

\footnotetext{
* Español. Coautor. Profesor de Geografía e Historia, Licenciado en Historia del Arte por la Universidad Complutense de Madrid, Máster en Investigación en Medios de Comunicación en la Universidad Carlos III. Candidato Doctor en Literatura Latinoamericana por la Universidad de Concepción y becario CONICYT-PFCHA/Doctorado Nacional/201721171064.davgarciareyes@gmail.com

** Español. Coautor. Doctor en Historia de América por la Universidad Pablo de Olavide de Sevilla (UPO). Magíster en Diplomacia y Relaciones Internacionales en la Escuela Diplomática de España. Máster en Europa, el Mundo Mediterráneo y su Difusión Atlántica en la UPO. Miembro de la Red de estudios comparados del Caribe y Mundo Atlántico (RECCMA). Actualmente es investigador en el Instituto de Salud Carlos III (ISCIII). xexuruiz@gmail.com
} 


\section{La Cuba de Pedro Juan bajo el período especial}

El periodo especial en tiempos de paz (1991-1995) que sufre Cuba marca un punto de inflexión que afecta de forma evidente la vida de los habitantes de la isla caribeña, dejando secuelas que siguen siendo palmarias dos décadas después. Los testimonios literarios favorecen el análisis del proceso histórico vivido por la sociedad cubana y reflejan un momento de enorme penuria y sufrimiento para el país caribeño. Desde un posicionamiento estético circunscrito al realismo sucio, uno de los autores que mejor atrapa esa realidad es el escritor habanero Pedro Juan Gutiérrez.

Los tres libros de cuentos de Pedro Juan Gutiérrez que conforman el volumen Trilogía sucia de La Habanal (TSH) son "Anclado en tierra de nadie"2, "Nada que hacer"3 y "Sabor a mí" ${ }^{4}$ y configuran el corpus del presente estudio.

Pedro Juan Gutiérrez nació en la localidad cubana de Matanzas en 1950. Su periplo biográfico puede verse en paralelo a la evolución de su país natal a lo largo de más de medio siglo. La existencia de Gutiérrez va de la mano de la Revolución Cubana (1959). El devenir vital del escritor se percibe en la capacidad de adaptación de un ser humano por encontrar su propio camino sin importar el éxito o el fracaso de su empresa.

De este modo, a lo largo de su vida Gutiérrez ${ }^{5}$ ha ejercido los más variados y singulares desempeños: trabajador agrícola y de la construcción, soldado, profesor de dibujo técnico, dirigente sindical, actor de radio, locutor y periodista. Además, presenta incursiones artísticas en los campos de la poesía visual, la escultura y la pintura.

Gracias a la literatura, el autor cubano se convirtió a finales del siglo pasado en un pequeño fenómeno editorial, auspiciado por el editor Jorge Herralde y la Editorial Anagrama. En su momento el lanzamiento de Gutiérrez por parte del sello barcelonés levantó ciertas suspicacias, pues se trataba de un autor desconocido con una edad muy alejada de lo que se puede considerar una promesa literaria o un escritor en ciernes.

La posterior carrera literaria de Gutiérrez confirma que era una realidad literaria y no una estrategia comercial. No obstante, tal y como argumenta Celina Manzoni ${ }^{6}$, los intereses editoriales signaron una operación crítica en el proceso de presentación de la primera obra publicada por el escritor de Matanzas. Además de la exótica y costumbrista presentación de Pedro Juan Gutiérrez en esta primera edición, la maniobra mediática puede considerarse como un movimiento para generar un fenómeno de ventas, rentabilizando la explosión en prosa del frenesí y la vida como fiesta del "paraíso" caribeño.

\footnotetext{
${ }^{1}$ Gutiérrez, P. J. (2008). Trilogía sucia de la Habana. Barcelona: Anagrama.

${ }^{2}$ Ibid, 7-125.

${ }^{3}$ Ibid, $127-218$.

${ }^{4}$ Ibid, 219-359.

${ }^{5}$ A partir de ahora, al referirnos a Pedro Juan será para hacerlo con el personaje y al mencionar al escritor cubano será a través de su apellido, Gutiérrez.

${ }^{6}$ Manzoni, C. (2011). "Violencia escrituraria, marginalidad y nuevas estéticas". Hipertexto 14, 60-61.
} 
A pesar del relativo éxito de público y crítica, y de haber editado en decenas de países, Gutiérrez no ha llegado a ser un "superventas" y el globo se hubiera desinflado hace tiempo sino contase con lectores fieles en más de una docena de idiomas. Por tanto, las coordenadas propuestas van encaminadas a elaborar un análisis de la prosa de los tres libros que componen $T S H$ y concretamente de los elementos vinculados a la identidad urbana del período especial en La Habana.

Uno de los objetivos es indagar el cambio histórico operado en el contexto cubano tras la caída del bloque soviético a principios de la década de los noventa del siglo pasado a través de un escritor contemporáneo. Se tratará, por tanto, de detectar cómo a través de los cuentos de Pedro Juan Gutiérrez se puede percibir el deterioro del proceso revolucionario y el estrangulamiento socioeconómico vinculado a las políticas de bloqueo de los Estados Unidos de América junto a la desaparición de la URSS como principal proveedor de la isla. Lo referido anteriormente está muy presente en la obra de Gutiérrez, no es raro comprender la precariedad y su avance in crescendo a lo largo de los diferentes cuentos de TSH. Una precariedad que, no obstante, alienta la capacidad de resistencia de los seres humanos que habitan en espacios de aparente degradación moral y física. A la vez, estos espacios son el germen de una literatura despojada de eufemismos y en los que se impone la cruda y rabiosa realidad del día a día de los sobrevivientes.

Es importante subrayar que el escritor cubano muestra su rechazo al discurso oficial. Desde su ejercicio como periodista ${ }^{7}$ ha sufrido la censura y, por eso, el suyo es el retrato de personajes fracasados. De ahí que rescate "el discurrir de esta praxis entre los resquicios de la oficialidad que la silencia o la censura". La metamorfosis que se opera en el periodista que entra en crisis y evoluciona hacia el escritor, cobra de esta manera un significado diferente en Gutiérrez, que se ve empujado "a otras posibilidades de ser y hacer" 9 . Un quiebre vital y decisivo para entender el posterior desarrollo de su obra.

En otro apartado de este texto se va a proceder a identificar algunas de las características que se producen en la construcción identitaria urbana de La Habana en la década de 1990. Ámbito espacial y temporal que se podría ceñir más específicamente a Centro Habana, municipio perteneciente a la provincia de La Habana y ubicado al norte de La Habana Vieja, donde el escritor ambienta la mayoría de sus relatos y donde se sitúa su residencia al momento de escribir la obra. En la construcción de la identidad, en la labor escritural del escritor cubano se puede percibir el discurso latente y doliente de Latinoamérica. No es de extrañar que en las diferentes entrevistas que concede a medios de comunicación, Pedro Juan Gutiérrez celebre lo periférico, subrayando la geografía y ensalzando la espiritualidad del subdesarrollo de los márgenes frente a la globalización monolítica.

\footnotetext{
${ }^{7}$ Resulta significativa la declaración de Pedro Juan en su condición de informador cuando afirma que "en más de veinte años de periodista nunca pude escribir respetando a los lectores. Al menos un mínimo de respeto por la inteligencia de los demás. No. Siempre tuve que escribir como si me leyera gente tonta, a la que había que inyectarle las ideas sistemáticamente en el cerebro". Gutiérrez, op. cit., 48.

${ }^{8}$ Yáñez Delgado, Y. (2009). "El discurso de lo cotidiano: margen, supervivencia y subversión en Trilogía sucia de La Habana, de Pedro Juan Gutiérrez". Contexto, 13-15, Vol. 13, 36.

${ }^{9}$ López de Jesús, L. I. (2014). "Endurecimiento, escritura y sobrevivencia en Trilogía sucia de La Habana", Cuadernos Americanos, 150, Vol. 4, 47.
} 
A diferencia de casos como el de la escritora Zoé Valdés y a pesar de las posibilidades de establecerse fuera de Cuba, Gutiérrez permanece en su terruño, que es Centro Habana donde, con sus espacios y su gente, le es suministrado el sustrato vernáculo de su literatura. Eso no significa que no sea crítico con el poder representado por las élites de la isla y los derroteros que ha tomado la Revolución, pues hasta en boca de los policías del cuento "Grandes seres espirituales", muestra su insatisfacción, pero a la vez honda resignación: "es verdad que aquí estamos pasando trabajo y hambre"

En las reflexiones de Roland Barthes sobre la mitología, se encuentra una reflexión de raíz etnográfica que orienta la comprensión de la representación del imaginario cultural cubano en relación a objetos y sujetos sociales, pues a partir de "la diferencia de las morfologías humanas, se cargan las tintas sobre el exotismo, se manifiestan las infinitas variaciones de la especie, la diversidad de las pieles, de los cráneos y de las costumbres, se babeliza a discreción la imagen del mundo"11. En esa idea de babelización, el espacio concreto de la obra de Gutiérrez proyecta un marco en el que los imaginarios colectivos nutren la formación de la identidad social y perpetúan la caracterización del cuerpo social cubano en el periodo especial. La obra del escritor no es un retablo historiado de la sociedad cubana, pero su análisis ofrece vectores que facilitan la exploración y el análisis de cómo se van conformando las identidades a partir de un momento crítico en la historia de la isla, alejándose de la realidad y de las rutinas de los cubanos del hombre nuevo alumbrado por Ernesto Guevara y optimizado por Fidel Castro durante el proceso revolucionario cubano.

Por extensión a los objetivos señalados, también se pretende detectar algunas de las tipologías urbanas descritas por Gutiérrez, poniendo especial énfasis en los marginales y excluidos que pueblan Centro Habana en TSH. Caracterizaciones en las que destacan las representaciones raciales y de género. En el relato "Salíamos de las jaulas", el autor afirma que "los mestizos son mucho mejores en todo que los negros puros y que los blancos puros. Es un buen negocio eso de la mezcla"12. Casi como si opusiese lo apolíneo a lo dionisiaco en clave niestzcheana, el escritor cubano ensalza y bendice la mezcla y el entorno: "el calor del trópico, la sangre latina, mi mestizaje fabuloso, todo conspiraba alrededor, como una red, incapacitándome para la soledad"13, aludiendo con ironía al hecho de no poder disfrutar de la soledad en el cuento "Solitario, resistiendo".

En este sentido, no podemos dejar de observar la influencia del pensamiento del antropólogo Fernando Ortiz en la obra de Gutiérrez. Las investigaciones de Ortiz fueron dirigidas a estudiar diversos aspectos de la cultura afrocubana, como la música, los ritmos y los bailes, lo que le llevó a elaborar uno de los conceptos más brillantes con los que consiguió definir la identidad cubana: la transculturación ${ }^{14}$. Esta manera de definir la

\footnotetext{
${ }^{10}$ Gutiérrez, op. cit., 77.

${ }^{11}$ Barthes, R. (1999). Mitologías. México DF: Siglo Veintiuno Editores, 178.

${ }^{12}$ Gutiérrez, op. cit., 138.

${ }^{13} \mathrm{Ibid}, 82$.

14 Veáse al respecto: Ortiz, F. (1940). Contrapunteo cubano del tabaco y el azúcar: advertencia de sus contrastes agrarios, económicos, históricos y sociales, su etnografía y su transculturación. La Habana: Jesús Montero. Fernando Ortiz propuso en esta obra por primera vez el concepto de transculturación para clasificar analizar el estudio del contacto cultural entre grupos diferentes. Ortiz consideró la transculturación como un proceso progresivo por el cual una cultura adopta y asimila rasgos de otra/s cultura/s para convertirse paulatinamente en una nueva e integradora cultura.
} 
creación nacional surgía al entender la cultura cubana como un proceso complejo de conformación continuo de distintos elementos y rasgos culturales temporales. Así, Ortiz consideró la identidad nacional cubana como una mezcla de culturas a lo largo de toda su historia hasta la actualidad: "La metáfora del ajiaco le sirve a Fernando Ortiz para definir la identidad cubana, este mestizaje continuo, permanente, en cambio y evolución, que producto de la transculturación, o mejor dicho de continuas transculturaciones, es la esencia de la cubanidad"15.

La necesidad de evitar disrupciones indeseables en la elaboración del presente estudio ha llevado a consultar la producción del propio Pedro Juan Gutiérrez en torno a su obra y a su condición como autor en su blog homónimo ${ }^{16}$. Teniendo en cuenta los objetivos de todo trabajo científico en cuanto al rigor se ha llevado a cabo un distanciamiento respecto a la bitácora de Gutiérrez, pues puede perjudicar al objeto de estudio y más teniendo en cuenta la capacidad de mixtificación que posee el escritor cubano en su condición de artista, en relación a su obra y a su propia vida.

\section{Miserias en Centro Habana: la crudeza de la precariedad}

Desde el relato que abre $T S H$, "Cosas nuevas en mi vida", la miseria se convierte en una constante estética y argumental de los relatos de Pedro Juan Gutiérrez. Este primer cuento funciona como introducción a la cruenta realidad que vive el personaje de Pedro Juan, álter ego del escritor y que aparecerá a lo largo de la mayoría de los relatos de la antología, narrados en primera persona y que dan cuenta de las diferentes vicisitudes que acontecen al personaje. La miseria sobrevuela los relatos y aparece al final en "Siempre hay un hijoputa cerca", como si fuera una letanía; Pedro Juan clama: "Cuba siempre ha sido igual: tres o cuatro años de abundancia y veinte de miseria" $"$.

Las situaciones de escasez material del denominado periodo especial abarcan desde 1991, con la caída de la URSS, hasta 1998, año en el que la Venezuela de Hugo Chávez atenúa los efectos del embargo estadounidense. Es en este tiempo, en el que se desarrolla y ambienta TSH. Esta situación de hambruna y necesidad hace que la antología de Gutiérrez despliegue "una actitud irreverente hacia la literatura"18, en parte como mueca caricaturesca y fundamentalmente como acto de liberación.

Tras la caída del muro de Berlín, el turbulento siglo XX parece el epílogo de un periodo histórico que se consume con la rapidez de un fósforo. El aparentemente sólido bloque comunista empieza a caer como un castillo de naipes e igual que en el lenguaje belicista de Estados Unidos, arrastra a numerosas víctimas colaterales. Daños nada colaterales son, sino más bien directos, los que causa el recrudecimiento del embargo de mercancías a Cuba.

\footnotetext{
${ }^{15}$ Naranjo, C. (2006). "Criollización y transculturación en la obra de Fernando Ortiz: un contrapunteo entre el pasado y el presente”. Caribe/Caribes: Criollización y procesos de cambio. Iberoamericana Pragensia, Editorial Karolinum 18, 20.

${ }^{16} \mathrm{http}: / / \mathrm{www}$. pedrojuangutierrez.com/

17 Gutiérrez, op. cit., 352.

${ }^{18}$ López de Jesús, op. cit., 57.
} 
Embargo vigente desde 1960 y que agravó la complicada situación económica de la isla con la aprobación de las leyes Torricelli en 1992 y Helms-Burton en 1996. Ambas leyes prohibían a las empresas norteamericanas invertir o comerciar con Cuba, así como recalar en puertos norteamericanos a barcos con mercancías cubanas ${ }^{19}$. Estas políticas de restricción comercial tuvieron como principal objetivo aislar y anular al gobierno "antidemocrático" de Cuba, afectando directamente a la población de la isla. A pesar de lo anterior, las estrategias de acoso no consiguieron "doblegar" el proceso revolucionario cubano, a cuenta eso sí, del éxodo de millones de cubanos y otras circunstancias que sirvieron de justificación al gobierno castrista para mantener un estado de excepción constante entre la sociedad cubana. La caída del orden soviético comenzó a notarse en la vida diaria de los cubanos a medida que su principal proveedor dejó de serlo. Progresivamente se produjeron, además de la migración por el estrecho de Florida, duras condiciones de escasez en el campo, por la falta de trabajo y de recursos, obligando a la gente de Provincias a intentar buscar acomodo y oportunidades en las ruinas de Centro Habana y otros municipios de la capital cubana.

La diáspora hacia Miami y la crisis de los balseros de mediados de los años noventa es referida en la obra de Gutiérrez. En el relato "Cosas nuevas en mi vida", el protagonista y narrador se pregunta si "sería buena idea tirar una balsa al mar por el cabo de San Antonio y llegar a cabo Catoche, o si es mejor salir por el norte directo a Miami. Eran los días del éxodo, en el verano del 94" "20. Para Gutiérrez y para su álter ego, Estados Unidos o Europa no son una opción. Pedro Juan, tal y como vemos recogido en los relatos de TSH, ha conocido el Berlín de la RDA, el sur de España, la gélida Suecia o el cosmopolitismo de Londres, pero Centro Habana es su lugar en el mundo y da igual que el hambre o la miseria sean el paisaje cotidiano. A pesar de las condiciones en las que vive Gutiérrez, Centro Habano no es un territorio impuesto, no se encuentra recluido o -en su propio lenguajeanclado a la "insularidad" de su espacio vital ${ }^{21}$.

La miseria aparece en toda su crudeza y la desesperación se hace notar cuando el personaje describe su situación en el relato "Aplastado por la mierda" y afirma que "ya estaba lo suficiente apaleado, sucio, barbudo y desesperado como para pedir limosnas. Fui hasta la iglesia de La Caridad, en Salud y Campanario, me senté en los escalones de la puerta, me quede con mi cara de hambre y desamparo, y extendí la mano"22. Pero ni siquiera la mendicidad le asegura un alivio transitorio a su situación de indigencia.

En ese espacio Pedro Juan reflexiona sobre la condición humana. A veces indiferente y primario se abandona con frecuencia a las urgencias más elementales y no siempre es la comida el apetito que necesita saciar. Aplacando la ansiedad de su perentorio instinto carnal, algo muy presente en la obra de Gutiérrez pues:

\footnotetext{
${ }^{19}$ Véase al respecto: Mesa-Lago, C. (2009). Historia de Cuba, Vol. 1, en Naranjo Orovio, C. (Directora), Historia de las Antillas. Madrid-Aranjuez: Doce Calles-CSIC, 522.

${ }^{20}$ Gutiérrez, op. cit., 9.

${ }^{21}$ Gurian, Max (2009). “Animales tropicales: Bestiarios poshistóricos en la literatura latinoamericana”. VII Congreso Internacional Orbis Tertius de Teoría y Crítica Literaria: 1-7, 3.

${ }^{22}$ Gutiérrez, op. cit., 59.
} 
El vínculo entre Cuba y el sexo es conocido y Gutiérrez lo explota. La sexualidad desaforada que se escenifica en esta novela se dispone también sobre la plataforma del espectáculo. Sexo y show (con sus vértices comerciales) aparecen representados alegóricamente a través de un personaje apodado 'Superman' ${ }^{23}$.

La pulsión del deseo, como motor de vida y creación escritural, le domina como si fuera un animal; animalización y animalidad presente en el conjunto de la obra literaria de Gutiérrez $^{24}$. El escritor cubano articula "espacios descentrados que muchas veces suelen coincidir con los del fuera de la ley [en un] espacio hostil bajo el cual el errabundeo se constituye en intemperie" 25 . Una marginalidad que como apunta Manzoni tiene que ver con la imagen y con la tipología del peligroso social, con los sujetos que se instalan en el extremo de la moral y de la ley. Una marginalidad y una aparente degradación de la que Pedro Juan no se avergüenza, porque lo prioritario para el personaje es sobrevivir en un contexto de devastación y periferia.

La Habana descrita en TSH es una ciudad desolada. En la capital cubana, la arquitectura y su no mantención se convierten en la ruina, un monumento al abandono. Algo que queda atestiguado el hecho de que el salitre caribeño lo inunde todo y busque con su lento percutir una decadencia secular y erosiva sin freno. Una situación que es producto del proceso político e histórico que vive Cuba en los años ya mencionados del periodo especial y la prosa de Gutiérrez se encarga de caracterizar sin sutilezas, dando una particular visión de la contemporaneidad.

La realidad de Pedro Juan es sobrevivir en un antiguo y decrépito bloque de departamentos. El ascensor hace tiempo que dejó de estar operativo y los vecinos pueblan de forma masificada y constante el edificio. Gutiérrez dibuja el hacinamiento y la insalubridad como una constante cotidiana. La llegada de más gente es consustancial al éxodo cubano. Los pobladores de La Habana que marchan fuera de la isla son sustituidos por los del interior, agudizando las duras condiciones y la falta de higiene, fruto de la masificación en la urbe caribeña. No es el único espacio en el que se refugia o cobija Pedro Juan, que también transita por solares abandonados o por casas de amistades, amantes y conocidos habituales o circunstanciales.

En este contexto de abyección, de degradación urbana y material, los personajes pugnan por resistir sin pararse a pensar en un futuro próximo. El axioma latino del poeta Horacio,

\footnotetext{
${ }^{23}$ Leal, Francisco (2005). “Trilogía sucia de La Habana de Pedro Juan Gutiérrez: mercado, crimen y abyección”. Taller de letras, 57. El comentario de Leal introduce el sexo, un elemento en el que coinciden varios autores a la hora de categorizar TSH. Leal considera TSH como una novela. En relación con el personaje de Superman se puede verificar que se trata de alguien que pertenece al imaginario folclórico habanero, tal y como como demuestran algunos testimonios que narran la escatológica anécdota que le vincula a la actriz Ava Gardner a finales de la década de 1950. Para lo anterior véase: Cabrera Infante, Guillermo (2001) Cine y Sardina. Madrid: Suma de Letras. 296.

${ }^{24}$ Particularmente destacable es el estudio de la animalidad en TSH de Sabrina Constanzo (2009). "Il rifugio nell'animalità: a proposito di Trilogía sucia de La Habana di Pedro Juan Gutiérrez", en AA. VV. Studi in onore di Candido Panebianco, offerti da colleghi e allievi di Ispanistica dell' Università di Catania, en el que la investigadora italiana presenta un acertado análisis del contexto histórico social de la obra de Gutiérrez y los elementos de la animalidad vinculada con el ámbito de la miseria y lo insalubre.

${ }^{25}$ Manzoni, op. cit., 59
} 
el carpe diem se reactualiza y adapta en los relatos del escritor cubano. Gutiérrez no ofrece una imagen condescendiente o idealizada de la decadencia de la capital cubana, al contrario, traza una cartografía emocional y física de los lugares y las situaciones menos atractivas para el lector. La soleada y exótica postal de viaje para el turista europeo de turno no se corresponde con las descripciones de Gutiérrez. A este respecto, Francisco Leal infiere que el escritor cubano plantea "la desaparición o sustitución de un cuerpo político colectivo por uno personal y masturbatorio [individualidad que aproxima a Gutiérrez/Pedro Juan como autor/personaje trabajando] con seducciones del género autobiográfico"26. La dualidad del escritor y del personaje, tal y como plantea Yáñez Delgado, lleva a la pregunta de ¿quién es Pedro Juan?, un juego del autor a modo de máscara que hace "imposible, acaso inútil, delimitar qué es lo autobiográfico"27.

En los relatos de Gutiérrez lo escatológico, lo visceral aparece de forma indisimulada, la deshumanización, o la animalización a la que se aludía anteriormente, se encuentra vinculada al proceso histórico como una "mutación de la biopolítica tropical" 28 , la última etapa de esa transculturación conceptualizada por Fernando Ortiz.

Un proceso que trae consigo tiempos de cambio, tiempos críticos, en los que el pasado, el devenir histórico y revolucionario, podría considerarse superado en la prosa de Gutiérrez, pues tal y como analiza Manzoni, evitando "el tono elegíaco [...] desaparece también la angustia del presente; incluso en la recuperación de un tono que podría pensarse como parodia de la picaresca [y] nunca se desdobla hacia la ironía" ${ }^{29}$. Gutiérrez presenta en el cambio "su marca definitoria, pues no hay manera de que se esté quieto. Antítesis de la institucionalidad y sus órdenes fijos, a este sujeto narrativo le está negada la posibilidad de echar raíces" $"$.

El estatuto como sujeto migrante de autor/personaje se relaciona con su condición de ciudadano de la periferia de la capital cubana, nacido y criado en Matanzas. También presenta la condición de ciudadano de la periferia del mundo, que esta encarnada por la geografía latinoamericana. La conceptualización del sujeto migrante de Antonio CornejoPolar se manifiesta en Gutiérrez a través de su lenguaje pues:

La condición migrante [...] habla con espontaneidad desde varios lugares, que son los espacios de sus distintas experiencias, autorizando cada segmento del discurso en un locus diverso. Con todo lo que ello significa, incluyendo la transformación de la identidad del sujeto, locus que le confiere un sentido de pertenencia y legitimidad y que le permite actuar como emisor fragmentado de un discurso disperso ${ }^{31}$.

\footnotetext{
${ }^{26}$ Leal, op. cit. 54.

27 Yáñez, op. cit., 38.

${ }^{28}$ Gurian, op. cit., 6.

${ }^{29}$ Manzoni, op. cit., 57.

${ }^{30}$ Yáñez, op . cit., 37.

${ }^{31}$ Cornejo-Polar, A. (1996). "Una heterogeneidad no dialéctica: Sujeto y discurso migrantes en el Perú moderno". Revista Iberoamericana, 176-177, 843.
} 
El "realismo sucio" de Pedro Juan Gutiérrez es una constante para la crítica precedente que se ha ocupado de la obra del autor cubano. Es importante apuntar que Gutiérrez conoce los textos de los clásicos norteamericanos de la literatura de "no ficción" como algunas obras de Truman Capote o Tom Woolfe con difusión en Cuba. Planteando el proceso de apropiación cultural desarrollado por Bernardo Subbercaseaux se infiere que la prosa del escritor cubano remite a autores norteamericanos anteriores a los citados como es el caso de la obra de Henry Miller. Pero no sería así con Charles Bukowski, pues Gutiérrez accede al grueso de la obra de Bukowski, parangón del realismo sucio norteamericano, después de la publicación de $\mathrm{TSH}^{32}$.

\section{Buscando identidades en Centro Habana}

La condición de periodista de Gutiérrez parece escorarse y "en medio de una crisis silenciada por el poder [...] el sujeto se construye voluntariamente al margen de la sociedad, para desde ahí atacar al centro, señalándolo acusatoriamente"33.

Reflejando lo extremo del autor/personaje se pude apreciar la identificación de Gutiérrez en relación al concepto de la cubanidad, una identidad en crisis y en constante cambio ${ }^{34}$. El proyecto identitario americanista vive un violento viraje durante el periodo especial en Cuba. La terrible situación del pueblo cubano y de su revolución no puede entenderse sin comprender lo que Roberto Fernández Retamar define como «nuestra propia realidad»y «nuestro propio lenguaje» ${ }^{35}$. Gutiérrez a pesar de su desafecto por la revolución no es ajeno a esa realidad, por eso plantea su propuesta desde América Latina.

La identidad urbana y por extensión la identidad cubana, tienen mucho que ver con nuevas formas de relacionarse a través de prácticas sincréticas como la Santería. En la actualidad, la Santería es una práctica religiosa que amalgama a "las vírgenes y santos de la tradición cristiana y los orishas o deidades de la cultura yoruba"36. En la obra de Gutiérrez, la práctica yoruba "no exige disciplina y orden, ni tampoco promete ambiciosos proyectos de transformación social" "37, de ahí la difusión y éxito que alcanza entre las clases populares cubanas.

En TSH además se puede reparar en "la consolidación del machismo en Cuba [a través de] la influencia de la cultura afro-cubana”. Los rituales yoruba son dirigidos por hombres, los babalaos, y las mujeres reciben un reconocimiento secundario como simples santeras ${ }^{38}$. El

\footnotetext{
${ }^{32}$ Para conocer algunos de los enfoques comparatistas entre el estilo de Henry Miller y Charles Bukowski con la literatura de Gutiérrez se puede acudir a Sueños y desencantos en novelas y películas cubanas del Periodo especial, tesis doctoral de Diana Sarabia (2007b), 128-132.

33 Yáñez, op. cit., 39.

${ }^{34}$ Manzoni, op. cit., 63-64.

${ }^{35}$ Fernández Retamar, R. (2000). Todo Calibán. La Habana: Letras cubanas, 72.

${ }^{36}$ Sarabia, D. (2007a). "El sincretismo yoruba-cristiano en Trilogía sucia de La Habana". II Jornadas de Investigación Literaria y Lingüística de los estudiantes Graduados del Programa de Español. Tinta virtual 2, 29.

${ }^{37} \mathrm{Ibid}, 31$.

${ }^{38}$ Sarabia, 2007b, op. cit., 100.
} 
mismo Pedro Juan no es precisamente un escéptico y siente más afinidad por Oggun que por el modelo revolucionario que representan Fidel Castro o Che Guevara. Lo anterior se puede percibir entre los siguientes relatos: "En busca de la paz interior", "My dear drum's master", "El recuerdo de la ternura", "Casino Esperanza" o "Yo claustrofóbico". Gutiérrez honra de este modo a "la tradición literaria cubana y continúa así la tarea de conservación iniciada por autores como Lydia Cabrera, Manuel Cofiño, Alejo Carpentier, Miguel Barnet, Lino Novas Calvo, Severo Sarduy y Benítez Rojo"39.

Las tipologías que pueblan la identidad cubana se pueden resumir y caracterizar en la figura del "pícaro" Pedro Juan, el cual a su vez se encuentra flanqueado por chulos oportunistas, jineteras, funcionarios, artistas o viudas venidas a menos, en su mayor parte viviendo en una decadencia mediada por el clima tropical y acuciados por el hambre y las necesidades más elementales.

Los personajes de Gutiérrez presentan una gran variedad de caracterizaciones. De esta forma encontramos a Robertico, migrante cubano que vive en Alemania con su rubicunda mujer en "Refrescando en La Habana"; sus dos hijos mulatos "deben ser los mestizos más privilegiados del mundo, porque la selección de padres era perfecta"40. A la condición de mestizos que otorga Pedro Juan, como evolución genética, se suma el hecho de que los hijos del emigrante cubano viven en un país del primer mundo, junto a la prosperidad económica para el escritor cubano lo mestizo se expresa como una mejora de la raza, no desde un darwinismo social, sino como expresión de la riqueza que supone la hibridez, aunque es muy escéptico del beneficio que los hijos de la pareja germano-cubana tengan en el contexto europeo de su condición mestiza.

En "Las puertas de Dios" se pueden extraer algunas de las opiniones de Gutiérrez en torno a la condición homosexual: "Los gays [sic] son una frontera entre la intranquilidad del black power y la calma relativa del Vedado. Parece más sedado. Pero no es así. Todo está contaminado. En definitiva, todos somos mestizos" ${ }^{41}$. En los relatos se puede entrever una normalización social de la condición homosexual y una equiparación con la heterosexualidad, algo que no se traslada en el reconocimiento de los derechos de los gais por parte del gobierno cubano, una normalización que no está exenta de contravenir la moral cristiana o revolucionaria: "Crucé la frontera gay, y recordé la parábola de los predicadores. Allí estaban todos pecando. Pecando frenéticamente" 42 .

Retomando la idea sobre la condición femenina en $T S H$, se puede señalar como las férreas estructuras de la sociedad machista del heteropatriarcado no están ni mucho menos desterradas en la Revolución cubana. Gutiérrez pone de relieve "un viejo problema social de Cuba y América Latina: el machismo. Un fenómeno alimentado por el modelo patriarcal europeo trasplantado al nuevo continente que, en el caso concreto de Cuba, se complementa con los aspectos de la cultura africana trasladada a la isla"43.

${ }^{39} \mathrm{Ibid}, 110$.

${ }^{40}$ Gutiérrez, op. cit., 156.

${ }^{41}$ Ibid, 176.

${ }^{42}$ Ibid, 178.

${ }^{43}$ Sarabia, 2007b, op. cit., 96. 
Esta objetivación de la mujer se puede leer "como una denuncia sobre los conflictos todavía no resueltos en la isla y América Latina"44, respecto a cuestiones como la igualdad de géneros y la consideración de la mujer. Lo que es evidente es que Gutiérrez enfatiza el interés y la mostración de la mujer y del cuerpo femenino, sin ponderar las capacidades y las virtudes intelectuales o sociales de la mujer ${ }^{45}$. Esta representación se vincula a un machismo que resulta conflictivo y que se percibe en el personaje de Luisa, mujer y mulata. Ella es la responsable del mantenimiento de la pareja que forma con Pedro Juan, primero trabajando en una fábrica de calzado y luego ejerciendo la prostitución para los turistas como jinetera en la Habana vieja, tal y como se describe en los relatos "Cosas nuevas en mi vida", "¡Ohh, el arte!", "Días de ciclón”, "Plenilunio en la azotea" o "El bobo de la fábrica". Gutiérrez no asume ninguna reivindicación, el suyo es un discurso individual en el que no toma conciencia ni defiende causa alguna, sea la crítica al racismo o la denuncia sexista.

\section{Reflexión}

Las caracterizaciones y representaciones del nuevo contexto surgido tras el fin de la Unión Soviética en Cuba marcan el devenir de la sociedad de la isla y, por medio de textos literarios, se pueden examinar la configuración de los imaginarios sociales y la cotidiana miseria de los individuos anónimos que sufren los avatares de la historia. A pesar del inmovilismo de sus gobernantes, los cubanos salen adelante con ingenio y a veces con pocos escrúpulos, evitando el control social y la represión del aparato gubernamental. Esa idea de resistir, de resistencia, frente al desarraigo y la miseria, es el motor que mueve a los personajes de Gutiérrez.

La estética de la miseria se concreta de forma material en las descripciones de los espacios urbanos que se distinguen por estar decrépitos, depauperados o ruinosos. Una cochambre que aparece sintéticamente descrita en el relato "Dos hermanas y yo en el medio":

Atravesé aquel barrio de gente muy pobre, pero al menos me respondían y me indicaron bien en aquel laberinto de casuchas de hojalata y maderas podridas y pedazos de ladrillos y cascotes desechados por la fábrica. Cuando llegué a la casuchita de Hayda, se estaba bañando ${ }^{46}$.

La imagen de ese espacio habitacional, reproducida a través de la literatura de Gutiérrez, retrotrae al lector a la conceptualización de lo que colige Beatriz Sarlo cuando se refiere a la ciudad de Buenos Aires en el último tercio del siglo XIX:

${ }^{44} \mathrm{Ibid}, 99$.

${ }^{45}$ Ibid, 104.

${ }^{46}$ Gutiérrez, op. cit., 24. 
En casi todos los barrios, crecía temporariamente una "ciudad efímera" de galpones de chapa levantados de un día para el otro, tapias contra las que se apoyaban precarios refugios, casuchas de madera armadas sobre el barro donde dormían los trabajadores recién llegados, los muy pobres, los vagabundos ${ }^{47}$.

La propia Sarlo confirma que esa ciudad efímera tendrá un carácter permanente y el modelo se extenderá por toda América Latina. No es de extrañar que, tras la hecatombe económica sobrevenida por el colapso soviético, los espacios residenciales en Cuba persistan con esta idea de precariedad y hacinamiento. Espacios para la narración y la convivencia que en TSH facilitan el reconocimiento de las tipologías de exclusión social en el contexto cubano. Irónica y tristemente, en mayor o menor medida, el conjunto de la sociedad isleña podría verse abocada a dicha exclusión, convirtiéndose no en una excepción sino en una tendencia casi normalizada.

El machismo implícito de TSH contrasta con la forma en la que el escritor visualiza la condición de los personajes homosexuales. Las alusiones podrían parecer despectivas, pero sin embargo no parodia la condición de la homosexualidad. Los personajes homosexuales en la obra del escritor tienen una identidad y una vida doméstica, contrastando con la negación de su vida pública y sus derechos en el ámbito reglado del estado cubano.

En cuanto al tratamiento de las mujeres, Gutiérrez no esconde su permanente necesidad de objetualizar a los personajes femeninos. Evita lo políticamente correcto al referirse a la condición femenina, pero, a pesar de todo, describe a los personajes femeninos con una fuerza de la que él carece. Con sus "armas", las mujeres en TSH se ven obligadas a ejercer la prostitución como jineteras con los turistas y a mantener a los miembros de su familia. De este modo, el personaje de Pedro Juan vive y se aprovecha del esfuerzo de algunas de las mujeres que aparecen en los relatos del libro. Se puede ver, así, la dicotomía o doble lectura: el tratamiento objetual del estatuto femenino frente a la capacidad de las mujeres para sacar adelante al hombre, todo ello en el contexto de una sociedad eminentemente machista.

Al analizar la obra literaria de Gutiérrez se puede percibir que la literatura es una expresión vital para él. El autor cubano, marginado en el ejercicio de la profesión periodística, está asqueado por no poder ser honesto con los que fueron sus lectores de la prensa escrita, intentando de este modo poder expresarse como un ser humano a través de lo que podríamos denominar como "realismo sucio tropical" o "literatura de no ficción a la cubana". Es de gran importancia entender que una de las mayores virtudes de sus relatos son la expresión de la "verdad" del autor, que intenta a través de su primer e "incontaminado" libro a nivel de recepción, abrir su ventana al mundo y enseñarnos esa cara poco amable de La Habana, muy alejada del romanticismo caribeño que venden las agencias de viajes y la industria hotelera instalada en la isla.

\footnotetext{
${ }^{47}$ Sarlo, B. (2009). La ciudad vista: Mercancías y cultura urbana. Buenos Aires: Siglo Veintiuno Editores, 59.
} 


\section{Referencias bibliográficas}

Barthes, R. (1999). Mitologías, México DF: Siglo Veintiuno Editores.

Cabrera Infante, G. (2001). Cine o Sardina, Madrid: Suma de Letras.

Constanzo, S. (2009). "Il rifugio nell'animalità: a proposito di Trilogía sucia de La Habana di Pedro Juan Gutiérrez", en AA. VV. Studi in onore di Candido Panebianco, offerti da colleghi e allievi di Ispanistica dell' Università di Catania, 53-66.

Cornejo-Polar, A. (1996). "Una heterogeneidad no dialéctica: Sujeto y discurso-migrantes en el Perú moderno". Revista Iberoamericana. Vol. LXII, 176-177, 837-844.

Fernández Retamar, R. (2000). Todo Calibán. La Habana: Letras cubanas.

Gutiérrez, P. J. (1998). Trilogía sucia de La Habana. Barcelona: Anagrama.

Gurian, M. (2009). “Animales tropicales: Bestiarios poshistóricos en la literatura latinoamericana", en VII Congreso Internacional Orbis Tertius de Teoría y Crítica Literaria, 1-7. Disponible en:

http://www.memoria.fahce.unlp.edu.ar/trab_eventos/ev.3556/ev.3556.pdf (Consultado el 2 de mayo de 2017).

Leal, F. (2005): “Trilogía sucia de La Habana de Pedro Juan Gutiérrez: mercado, crimen y abyección", Taller de letras, 37, 51-66.

López de Jesús, L. I. (2014). "Endurecimiento, escritura y sobrevivencia en Trilogía sucia de La Habana", Cuadernos Americanos, 150, Vol. 4, 45-59.

Manzoni, C. (2011). "Violencia escrituraria, marginalidad y nuevas estéticas", Hipertexto, 14, 5770.

Mesa-Lago, C. (2009), Historia de Cuba, Vol. 1, en Naranjo Orovio, C. (directora), Historia de las Antillas, 5 Vols., Madrid-Aranjuez: Doce Calles-CSIC.

Naranjo, C. (2006). "Criollización y transculturación en la obra de Fernando Ortiz: un contrapunteo entre el pasado y el presente”, en OPATRNÝ, J. (Ed.), Caribe/Caribes: Criollización y procesos de cambio, Iberoamericana Pragensia, Editorial Karolinum, 18, 11-24.

Ortiz, F. (1940). Contrapunteo cubano del tabaco y el azúcar: advertencia de sus contrastes agrarios, económicos, históricos y sociales, su etnografía y su transculturación, La Habana: Jesús Montero.

Sarabia, D. (2007a). "El sincretismo yoruba-cristiano en Trilogía sucia de La Habana", en II Jornadas de Investigación Literaria y Lingüística de los estudiantes Graduados del Programa de Español. Tinta virtual, 2, 28-36. Disponible en:

http://aix1.uottawa.ca/ gbara083/Pages/Tintavirtual02/II\%20Jornadas-Sarabia.pdf (Consultado el 7 de abril de 2017).

Sarabia, D. (2007b). Sueños y desencantos en novelas y películas cubanas del Periodo especial. Tesis presentada en la University of Ottawa, Ontario. Disponible en:

https://www.ruor.uottawa.ca/bitstream/10393/29695/1/NR49396.PDF (Consultado el 4 de mayo de 2017). 
Sarlo, B. (2009). La ciudad vista: Mercancías y cultura urbana, Buenos Aires: Siglo Veintiuno Editores.

Subbercaseaux, B. (1991). Historia, Literatura y sociedad (Ensayos de hermenéutica cultural), Santiago: Documentas/CESOC/CENECA.

Yáñez Delgado, Y. (2009). "El discurso de lo cotidiano: margen, supervivencia y subversión en Trilogía sucia de La Habana, de Pedro Juan Gutiérrez”. Contexto, Vol. 13, 15, 37-47. 